$32^{\text {nd }}$ European Modeling \& Simulation Symposium

$17^{\text {th }}$ International Multidisciplinary Modeling \& Simulation Multiconference

ISSN 2724-0029 ISBN 978-88-85741-44-7 (c) 2020 The Authors.

DOI: $10.46354 /$ i3m.2020.emss.035

\title{
Synchronization of public passenger transport subsystems using stochastic simulation: the case of lines with longer headway times
}

\author{
Josef Bulíček ${ }^{1, *}$, Pavel Drdla ${ }^{1}$ and Jaroslav Matuška ${ }^{1}$ \\ ${ }^{1}$ University of Pardubice, Faculty of Transport Engineering, Studentská 95, Pardubice, CZ-532 10, Czech Republic \\ ${ }^{*}$ Corresponding author. Email address: josef.bulicek@upce.cz
}

\begin{abstract}
This paper is focused on timetable synchronization of urban, regional and long-distance public passenger transport subsystems in stochastic conditions. Proposed method is based on a mesoscopic simulation model. Model is applied within a process (method) leading to a robust timetable in the point of view of passengers changing e.g. from trains to buses of urban public transport. Solution is focused on specific condition - the case of relative long time headways between individual services of public transport like 30, 60 or 120 minutes, so that possible time loss can be serious. There are a number of such cases in reality. It is typical for small and medium sized cities or municipalities. Some lines with similar headway time can be found in large cities as well. Solution is illustrated by the case study focused on interchange node located in Ždár nad Sázavou (Czech Republic). Modified approach to generating of train input delays allowing to take overall operational situation on railway infrastructure into account (e.g. influence of construction works) is presented as well. This is compared to the way based on generation of delays in an individual way for individual trains.
\end{abstract}

Keywords: Delay; interchange node; public passenger transport; simulation model; timetable synchronization

\section{Introduction}

Operational reliability is a key feature of interchanges in public passenger transport. The paper is focused on interchange node between trains and urban buses. Presented method can be generalized on all nodes where time headways between individual transport services are long (like 30,60 or $120 \mathrm{~min}$ ) so that serious time loss can be occurred in the case of loss of connection.

The main aim of the paper is to demonstrate a method for design of a robust timetable (in point of view of interchanges). The method is based on a stochastic simulation model.

Stochastic generation of input time delays of trains is essential for such simulation. It is discussed as a secondary topic. In fact, each train gets individually generated value of delay in the model. The delay values can be influenced by operational conditions (like construction works on the line) in similar way by more trains. Individual generation can possibly lead to unrealistic structure of delays in replication. Modified way (with 2 steps) for generation is introduced.

Research is demonstrated in practical conditions of Ždár nad Sázavou. It is a city with $21 \mathrm{k}$ inhabitants located almost in the middle of the Czech Republic (about $150 \mathrm{~km}$ southeast of Prague).

There are 3 regional and 1 long-distance railway line connected with 9 urban public transport (UPT) bus lines at the solved node (railway station). Railway

(C) 2020 The Authors. This article is an open access article distributed under the terms and conditions of the Creative Commons Attribution (CC BY-NC-ND) license (https://creativecommons.org/licenses/by-nc-nd/4.0/). 
lines are operated with time headway of 6omin or 120min. Main UPT transport bus lines are operated with headway of 6omin. Therefore, this node has ideal conditions for demonstration of topic.

Applied simulation model is mesoscopic, because some of features are individualized. Macroscopic (generalized) solutions are often based on evaluation of total time consumption counted for all passengers (Hernandez and Monzon, 2015). Issue is that time savings for one passenger can be related to time loss of other passenger by using of this aggregated approach. Proposed method of modelling and synchronization replaces time consumption (or similar criterions) by quality-based indicators evaluating interchanges.

Applied simulation model has been developed in Microsoft Excel by using of Visual Basic for Applications programming language. This approach is applied due high flexibility for research purposes.

\section{State of the art}

The authors of this paper conduct research in the field of public passenger transport for a long time. Applied qualitative indicators as well as the way of simulation have been introduced within a habilitation thesis of one of the authors (Bulíček, 2015). Timetable synchronization in busy hubs of public transport is taking a part of the paper (Bulíček, 2018), but stochastic aspect was not followed there.

Earlier results of research in field of demand for public transport and in the field of modelling of passengers' decision-making processes are published e.g. by Kleprlík and Matuška (2017).

Timetable synchronization problem is a frequently solved research topic. On the other hand, this topic has many forms and links to other circumstances.

Integrated railway network point of view on timetable and its optimization can be represented by Yizhen et al. (2020) presenting mixed-integer optimization model for design of a rail network timetable with minimized transfer times.

Synchronization of timetables in UPT (bus) networks is solved by Abdolmaleki et al. (2019). Optimization problem with congruence constraints is applied as the base for solution.

Another point of view on bus timetables is presented by Ceder et al. (2001). The paper (Blanco et al., 2020) is focused on timetables of automated metro subway networks.

Specific question of synchronization of timetables of last trains (before operation brake - e.g. at night) with an effort to maximize the weighted sum of accessible origin-destination pairs (by last services) is solved by Chen et al. (2019). It is based on mixed integer linear programming model as well.

Optimization of timetables with regard on vehicle capacity utilization is highlighted by Xue et al. (2019).
Nonlinear integer programming model and a genetic algorithm are applied for improving of efficiency.

Rescheduling of timetables in dense railway network with focus on infrastructure capacity and (it could be told) operation stability is a scope of the paper (Altazin et al., 2020). Multi-objective optimization is combined with macroscopic simulation in this case.

Relation between shortening of travel times and punctuality of operation in railway transport is researched by Högdahl at al. (2019).

Similar theme like in this paper is solved by (Naumov, 2020). Rationalization of total waiting time of passengers is followed, but the approach based on genetic algorithms is different.

Second similar topic is presented by Monzon et al. (2017). The paper is focused on interconnection on long-distance and local public transport in different European cities. There is mentioned also the relation on European projects HERMES, NODES, City-HUB that belong to core project activities in this field.

There are a number of papers related to the simulation modelling as well. The paper Sever et al. (2018) is focused dynamic microsimulation models of traffic flow. There is mentioned a 5-step structure of modelling (model establishment; random generation of a problem in the network; 2 different ways of solution to be compared and comparison of results). Modified, but similar structure is applied for modelling of operational situation in railway transport by generation of input delays of trains in our simulation model.

The main focus is put on development of timetable optimizing models nowadays. Issue is that computing demands are high and heuristic algorithms are often needed. Application of descriptive simulation models is common e.g. in railway transport with possibility to find suitable results (in spite the fact that these results do not have to be optimal in the mathematical point of view). For these reasons our research is focused on application of stochastic simulation in case of an individual interchange point where longer time headways are applied. There is an effort to create method to allow basic synchronization of timetable as a support for transport designers. This makes also a difference from previous publications of the authors.

Transfer time as time needed for change from one vehicle to another is crucial. Walking distances, number of elevators and escalators or access to information are key aspects influencing transfer time according to Hernandez and Monzon (2015). Optimization of flows of passengers changing between transport services is discussed by Wang (2019). Routing of these flows is important for reduction of transfer time. Short waiting times at interchange node is very important for more than $60 \%$ of passengers and short distances needed to be passed for more than $51 \%$ of passengers according to Oostendorp and 
Gebhardt (2018). Some authors are focused on specific interchange nodes like Popovic et al. (2012) dealing with Beograd Centar Station (Serbia). Specific needs of people with reduced mobility are accented as an important aspect.

\section{Materials and Methods}

Presented research is focused on 2 issues -timetable synchronization and modified generation of train time delays as inputs into replications of stochastic simulation.

\subsection{Research hypothesis}

"It is possible to develop an optimizing method using results of stochastic mesoscopic simulation model able to be applied for improvement of timetable synchronization at an interchange node with longer time headways between individual public transport services."

Secondary hypothesis is related to the way of generation of values of input delays. "Separated simulation (generation) of variant of operational conditions and using of associated values of delay will provide more realistic results than generation of delay using the same parameters of probability distribution for each train and conditions."

\subsection{Method}

Simulation model is taking main part in proposed timetable synchronization method.

\subsubsection{Starting point}

Extent of operation, timetable and other features of regional and long-distance (railway) transport are considered as given with no possibility to be changed within optimization. Long-distance and regional lines are usually limited by a number of other conditions. For example capacity issues in relation to timetable are mentioned e.g. by Široký et al. (2019). On the other hand, these arrivals are simulated in stochastic way. Timetable can be also filtered by time, weekday, line and direction for possibility to make sub-models (to solve partial optimization tasks).

The aim is to synchronize UPT to other lines. UPT arrivals and departures are changeable within optimization. It corresponds to a common reality. UPT arrivals and departures can be modified to the extent possible (with respect to possible constraints). Operation of UPT is modelled as deterministic (no delays). The reason is that UPT operation is considered as more reliable and that passengers follow especially timetable by decision to use interchange.

\subsubsection{Model inputs and model variables}

Simulation model is designed for time period of $24 \mathrm{hrs}$ (to be considered) and it is based on following inputs. The main input is set of arrivals of trains. These data are supplemented by information about probability features of possible delay, by time restrictions on operation (e.g. transport service not available on weekend) and by one, two or three so called destination profiles for evaluation (please see chapter 3.2.3).

UPT services are inserted as a set of time positions of departures to be considered. In the case of UPT lines in different directions, more model variants with different sets of UPT departures can be applied.

Analogic inputs and processes can be applied for modelling of changing from UPT to railway as well. Last, but not least segment of inputs is related to specification of interchange time limits (please see chapter 3.2.4).

\subsubsection{Destination profile}

So called "destination profile" is a core concept for proposed model and method. It is a place (locality) out of the city from (to) where passenger can travel. Profile can stand for e.g. neighbour city or for a set of municipalities located on solved line or for other important places (e.g. tourist attraction, ski resort etc.).

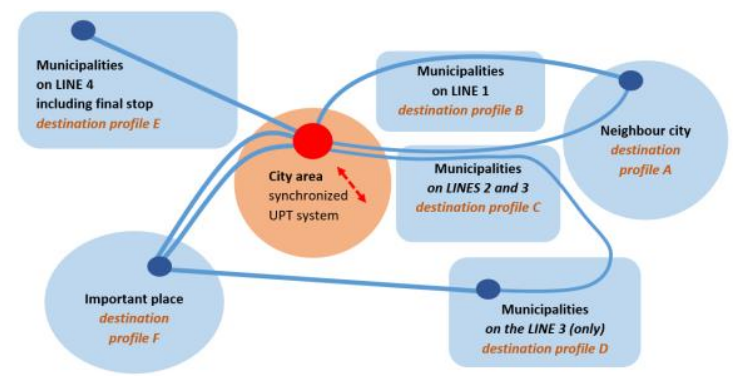

Figure 1. Example of destination profiles.

Source: Authors, based on results of (Bulíček, 2015).

Interchanges are considered between set of trains going from destination profile and set of UPT services. When there are more lines (e.g. to the next city), transport supply is considered as aggregated. Please see Figure 1 for illustration of this concept. Destination profiles can be weighted when it is needed.

\subsubsection{Criterion}

Passengers would like to reduce time spent by travelling (Oostendorp and Gebhardt, 2018). The question is if this time should be strictly minimal or if it can be in some acceptable range.

Individual cases of interchange (between trains of destination profile and UPT bus services) are categorized and evaluated by points, please see Table 1. 
Table 1. Categories of interchange. Source: Authors

\begin{tabular}{|c|c|c|}
\hline Category & Time span [min] & Points \\
\hline Impossible & $<0 ; 3)$ & -0.5 \\
\hline \multicolumn{3}{|c|}{ Lack of time to move between platforms or stops. } \\
\hline Uncomfortable & $<3 ; 6)$ & 0.2 \\
\hline \multicolumn{3}{|c|}{$\begin{array}{l}\text { Interchange in a hurry with no possibility to get information, } \\
\text { purchase tickets etc. }\end{array}$} \\
\hline Ideal & $<6 ; 11)$ & 1.0 \\
\hline \multicolumn{3}{|c|}{$\begin{array}{l}\text { Possibility to go free, to make basic acts (e.g. to purchase ticket), } \\
\text { possibility to interchange for people with reduced mobility (e.g. } \\
\text { using lifts, longer barrier-free routes etc.). }\end{array}$} \\
\hline Long & $<11 ; 15)$ & 0.6 \\
\hline \multicolumn{3}{|c|}{ Acceptable, but with feeling of time loss. } \\
\hline Not connected & $<-7 ; 0)$ & -0.5 \\
\hline \multicolumn{3}{|c|}{$\begin{array}{l}\text { Departure (of UPT bus) is in defined time frame before arrival (o } \\
\text { train). }\end{array}$} \\
\hline
\end{tabular}

Mentioned categories have been introduced by Bulíček (2015). Now, it is equipped by point evaluation. When transfer time is ideal, 1 point is assigned. Point value is reduced in all other cases due to discomfort. Impossible and not connected interchanges can get negative value for strengthening of prevention of such cases. The aim is to maximize total amount of points.

This approach is reflecting two important aspects. It is usually not possible to find optimal solution at all possible interchange relations (from/to all destination profiles). These cases are considered as "neutral" (o points in criterion). On the other hand, maximization of points "prefers" suitable interchanges. The second aspect is if passengers are considering interchange time with resolution of 1 minute or with "binary" evaluation as un-/suitable. It can be a theme to discussion.

\subsubsection{Optimization part}

Simulation model has results of descriptive character, but these results can be applied for optimization of timetable (interchange).

Simulation can be conducted in two ways and both are applied. Deterministic simulation (fully punctual operation of railway) is used for determination of time position for departures of UPT bus services; stochastic for assessment of punctuality and then for possible rescheduling of UPT departures. Details are mentioned in chapter 4.

Optimizing part of the method is supported by developed exhaustive-search algorithm. This algorithm with computer support is dedicated to lines with periodic operation. Regular time headway between services and extent of operation (time from to) can be set by user. Algorithm tests all possible variants of solution (time positions of UPT bus departures). Each evaluated by deterministic situation.

\subsubsection{Generation of stochastic inputs}

Delays of trains are modelled stochastically within assessment of punctuality.

Issue is that there are some aspects influencing the overall situation in railway transport operation in general. It means that at least subset of trains (e.g. on one line) has similar level of delays. Application of one general probability distribution can lead to the fact that one train can have e.g. no delay and the second one high delay. It can be unrealistic in combination.

Construction works on infrastructure, conditions related to (bad) weather, operational irregularities can be mentioned as examples of such aspects. The set of situation is not finite and it must be determined with regard to local specific conditions.

In consonance with secondary hypothesis of this research, two ways of generation of stochastic inputs are applied. The first is related to application of one general probability distribution for all cases. The second is two-step generation (modelling) when the overall situation is generated individually as the first and then the delay value according to associated probability distribution as the second step.

This hypothesis was tested by the year 2015 where 8 months were connected to long-time lasting construction works on railway line and 4 to "standard" operation. It was found out that delay probability distributions for individual months do not correspond to general probability distribution for all the year (by using of chi-square test). For simply illustration, values of average delay can be compared. Maximal value of average delay in monthly expression was $5.43 \mathrm{~min}$, minimal $1.44 \mathrm{~min}$ and year-based was $3.05 \mathrm{~min}$. Two-step generation of delay values can be recommended due to this.

\section{Results and Discussion}

The case study is focused on interchange from trains to UPT buses in Ždár nad Sázavou as it was mentioned. Case study is located to year 2020, but with delay characteristics from 2015 (illustration of construction works influence) and 2019 (the same operation conditions).

Transport is operated from $4 \mathrm{AM}$ until $11 \mathrm{PM}$. Connection to 1 model UPT bus line with headway time of 6omin is considered in the case study. UPT line operation is periodic (bus departure at the same minute every hour). It corresponds to lines No. 2 and 8 in practice. Services of both lines depart at the same time of X:40. Routes of both lines are different.

Railway transport is almost periodic. Trains of all lines typically arrive and depart between X:20 and $\mathrm{X}: 38$. Please see Figure 2. 


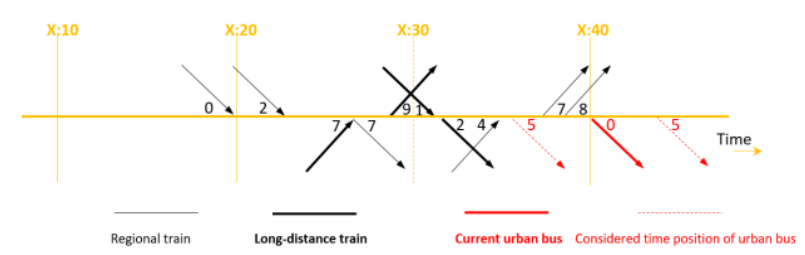

Figure 2. Interchange relations in Ždár nad Sázavou. Source: Authors, based on (IDOS, 2020).

\subsection{Deterministic simulation - experiments}

Deterministic simulation is applied for optimization of time position of UPT bus departures. There are 60 variants considered by the algorithm (from 0 to 59min). This is extended (repeated) from $4 \mathrm{AM}$ to 11 PM every hour in the same way. Total amount of points is computed by simulation for every variant. Please see the results in Figure 3.

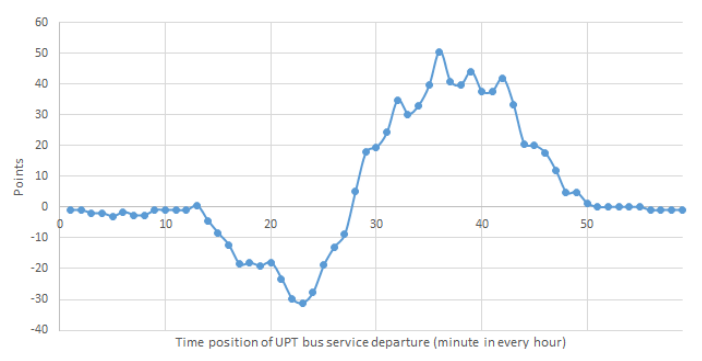

Figure 3. Evaluation of UPT departure time positions. Source: Authors.

The best time location of UPT is X:35 according to deterministic simulation (50.6 points), the $2^{\text {nd }}$ is X:38 (44.0), the $3^{\text {rd }} \mathrm{X}: 41$ (41.8). The worst is $\mathrm{X}: 22(-31.1$ points).

\subsection{Stochastic simulation - experiments}

Second step is to evaluate results by stochastic simulation (bdelay of trains). A part is made using punctuality of the year 2019 with application of general (the same) probability distribution of delays. Departure time positions from X:35 to X:45 were examined in this way, each by 1095 stochastic replications (3 years) and with the same simulation seed (for comparability). Please see Figure 4 for results. Average, maximal and minimal values are displayed. Values from deterministic simulation are added.

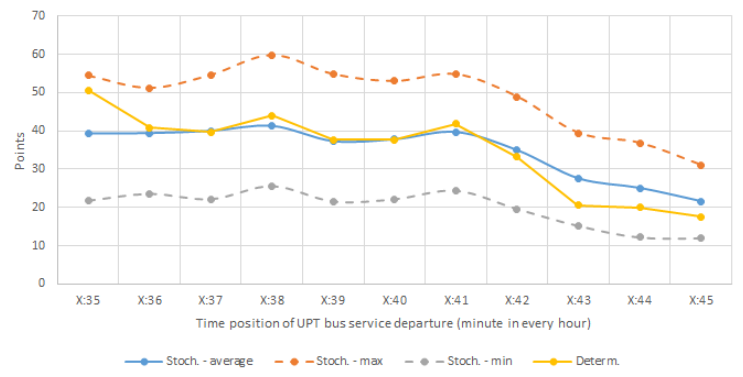

Figure 4. Stochastic evaluation of UPT departure time positions (X:35 - X:45). Source: Authors.
Proposed approaches to generation of input train delays are analysed by the year 2015 (construction works) and for state-of-art departure time position of $\mathrm{X}: 40$, see Table 2.

\begin{tabular}{llllll} 
Table 2. Generation of input delay. Source: Authors \\
\hline Case* [points] & 1 & 2 & 3 & 4 & 5 \\
\hline Departure & \multicolumn{5}{|c}{ X:40 } \\
Determ. & \multicolumn{5}{c}{37.6} \\
Stoch. - average & 35.7 & 38.4 & 32.4 & 38.4 & 29.2 \\
\hline
\end{tabular}

$*_{1}$ - General distribution; 2 - All trains, standard operation; 3 - All trains, construction works, 4 - Individual distribution for each railway line, standard; 5 - Indiv. distr., construction works.

Evaluation of 4 different departure time positions by using of recommended two-step generation of input delays is in Table 3.

Table 3. Simulation by two-step generation of delays. Source: Authors

\begin{tabular}{lcccc}
\hline Case [points] & 6 & 7 & 8 & 9 \\
\hline Departure & $\mathrm{X}: 35$ & $\mathrm{X}: 40$ & $\mathrm{X}: 43$ & $\mathrm{X}: 45$ \\
Determ. & 50.6 & 37.6 & 20.6 & 17.6 \\
Stoch. - average & 31.2 & 32.4 & 28.3 & 23.4 \\
\hline
\end{tabular}

\subsection{Discussion}

Some important facts can be discussed based on reached results. There is a suitable distribution of trains in time in this case study. Resulting time position from deterministic simulation is $\mathrm{X}: 35$. It corresponds with the structure of planned train arrivals (please compare Figures 2 and 3), but too early after "last" train arrival (X:34). It is due to effort to "serve" train arrivals at X:20 and X:23.

Departure time position at $\mathrm{X}: 35$ is attractive as planned, but not too much suitable from the point of view on punctuality. Please compare brown and blue graph in the Figure 4. Deterministic (planned) and "average" (stochastically simulated) numbers of point are almost similar for departures in time span of X:36 - X:41. Stochastic results are better than planned for time position $\mathrm{X}: 42-\mathrm{X}: 45$. It is due to time reserve by interchange and due to shortened interchange time (caused by delay), but overall tendency is decreasing. It is caused by the fact that UPT departure is coming to be too late after planned train arrivals.

With regard to the fact that local authority requires UPT departures $\mathrm{X}: \mathrm{X0}$ or $\mathrm{X}: \mathrm{X} 5$, recommended time position should be rescheduled to $\mathrm{X}: 40$. This is second advantage of this method. Other variants than optimal can be also considered. These variants can be important for local reasons as well.

\section{Conclusions}

The conclusion is that it is possible to find the method for synchronization of timetables based on simulation. Two-step generation of input delays can be also useful, see Tables 2 and 3. Input hypotheses are not able to be rejected by results mentioned in this paper. 


\section{References}

Abdolmaleki, M., Masoud, N., and Yin, Y. (2019). Transit timetable synchronization for transfer time minimization. Transportation Research Part B, 131 (2020) 143-159.

Altazin, E., Dauzère-Pérès, S., Ramond, F., and Tréfond, S. A multi-objective optimizationsimulation approach for real time rescheduling in dense railway systems. European Journal of Operation Research, 286 (2020) 662-672.

Blanco, V., Conde, E., Hinojosa, Y., and Puerto, J. (2020). An optimization model for line planning and timetabling in automated metro subway networks. A case study. Omega, 92 April 2020, 102165.

Bulíček, J. (2015). Integrace systémů osobní dopravy technologie provozu přestupních uzlů. (Integration of passenger transport systems - Technology of operation of interchange nodes). Thesis (in Czech). University of Pardubice, 2015.

Bulíček, J. (2018). Timetable synchronization: Urban public transport in busy hubs of long-distance transport. MATEC Web of Conferences, 239: article number02001.

Ceder, A., Golany, B., and Tal, O. (2001). Transportation Research Part A, 35 (2001) 913-928.

Hernandez, S., and Monzon, A. (2016). Key factors for defining an efficient urban transport interchange: Users' perceptions. Cities, 50, 158-167.

Högdahl, J., Bohlin, N., and Fröidh, O. (2019). A combined simulation-optimization approach for minimizing travel time and delays in railway timetabes. Transportation Research Part B: Methodological, 126 (2019), 192-212.

Chen, Y., Mao, B., Bai, Y., Ho, T.K., and Li, Z. (2019). Timetable synchronization of last trains for urban rail network with maximum accessibility. Transportation Research Part C, 99 (2019) 110-129.

IDOS (2020). Online timetable information system IDOS. portal.idos.cz

Kleprlík, J., and Matuška, J. (2017). The demand for public transport and modelling decision-making process of passengers. Transport Means 2017 (21), 197-202.

Monzon, A., Alonzo, A., and Lopez-Lambas, M. (2017). Joint analysis of intermodal long distance-last mile trips using urban interchanges in EU cities. Transportation Research Procedia; 27 (2017) 10741079.

Naumov, V. (2020). Genetic-based algorithm of the public transport lines synchronization in a transfer node. Transportation Research Procedia, 47 (2020) 315-322.

Oostendorp, R., and Gebhardt, L. (2018). Combining means of transport as a users' strategy to optimize traveling in an urban context: empirical results on intermodal travel behavior from a survey in Berlin. Journal of Transport Geography, 71, 72-83.

Popovic, Z., Puzavac, L., and Lazarevic, L. (2012). Improving the accessibility of passenger railways in the Republic of Serbia. RTR-Railway Technical Review-English Edition, (2), 25.

Sever, D., Lutar, R., and Toplak, S. (2018). Assessment of Possibilities of On-Line Response Dynamic Traffic Management System Development in Medium Size Urban Areas. Tehnički vjesnik, 25, no. 5 (2018) 1478-1484.

Široký, J., Šrámek, P., Magdechová, K., Tischer, E., and Hlavsová, P. (2019). Timetable performance evaluation. In Transport Means: proceedings of the international scientific conference. Kaunas: Kaunas University of Technology (2019) 1427-1432.

Wang, D. (2019, August). Research on Optimization of Passenger Flow Organization in Passenger Transport Stations during Peak Period. In $1^{\text {st }}$ International Symposium on Innovation and Education, Law and Social Sciences (IELSS 2019). Atlantis Press.

Xue, Q., Yang, X., Wu, J., Sun, H., Yin, H., and Qu, Y. (2019). Urban Rail Timetable Optimization to Improve Operational Efficiency with Flexible Routing Plans: A Nonlinear Integer Programming Model. Sustainability, 2019, 11(13), 3701.

Yizhen, W., Dewei, L., and Zhichao, C. (2020). Integrated timetable synchronization optimization with capacity constraint under time-dependent demand for a rail transit network. Computers \& Industrial Engineering, 142 (2020) 106374. 